\title{
LOS DERECHOS DE INDIOS Y ESCLAVOS REALISTAS Y LA TRANSFORMACIÓN POLÍTICA EN POPAYÁN, NUEVA GRANADA (1808-1820)
}

POR

\author{
MARCELA ECHEVERRI
}

College of Staten Island. City University of New York

\begin{abstract}
Éste es un trabajo sobre el entendimiento y la defensa estratégica del discurso realista por parte de indios y esclavos en la provincia de Popayán, desde 1808 hasta 1820. Durante la crisis de la monarquí, tal como lo habian hecho antes, indios y esclavos buscaron beneficiarse del contexto político y dar nueva forma a sus derechos a través de su constitución como aliados de los realistas. A través del estudio de esas alianzas al comienzo de la guerra, este trabajo aporta una imagen dinámica del realismo popular que resalta la compleja articulación social y la participación política de indios y esclavos en el proceso de la transformación política en Popayán.
\end{abstract}

Palabras clave: Realismo, indios, esclavos, derechos, pacto, libertad, liberalismo.

Desde que se consolidó el poder hispano en América en el siglo XVI, indios y esclavos daban a la ley, al sistema judicial y a otras instituciones hispánicas como la religión católica usos diversos en la construcción y defensa de sus derechos. Los indios adquirieron derechos, o privilegios, como vasallos del rey y la Corona estableció instituciones que facilitaron su aplicación a diferentes niveles (las Cortes y el protector de indios). Aunque se ha argumentado que la ley jugó un papel central en la sujeción de los indios, expresada en la consolidación de la categoría legal de «indio», también es posible reconocer una relación positiva de los indios con ésta. Por una parte, ello se refleja en la oportunidad cotidiana y difundida que éstos tenían de apelar ante las instituciones monárquicas por la protección real. Por otra, los indios también incidieron en la construcción estructural de las categorías y los me- 
canismos jurídicos que vinieron a caracterizar el paternalista derecho hispánico ${ }^{1}$.

Paralelamente, aunque por muchos años la historiografía ubicó a los esclavos por fuera de la vida política y jurídica colonial, ellos también estuvieron profundamente implicados en las dinámicas locales e imperiales. Los africanos esclavizados fueron agentes muy activos. Enterados de las discusiones legales que les competían, se apropiaron de conceptos centrales relativos al gobierno terrenal y de las almas, transformando con su práctica las posibilidades de control con que el sistema buscaba apresarlos. Sus estrategias legales al respecto iban desde aprovechar los espacios y derechos mínimos que se les otorgaba desde la antigüedad (las Siete Partidas) hasta valerse de las circunstancias locales (cambios en legislación, enfrentamiento entre las elites) que con un poco de suerte podrían resultar en su beneficio ${ }^{2}$.

En el siglo XVIII, la legislación borbónica relativa a ambos grupos tuvo consecuencias sobre su relación con la Corona y las instituciones locales. El caso de la provincia de Popayán, en el Nuevo Reino de Granada, permite entender cómo a lo largo de ese siglo se transformó la relación de indios y esclavos con la monarquía hispánica mientras los términos del gobierno imperial se ajustaban a un nivel más amplio. Por ejemplo, las comunidades indígenas, que sumaban el 50\% de la población en el distrito de Pasto, reaccionaron contra las políticas de extracción del nuevo gobierno que fortalecían al corregidor en detrimento de las autoridades tradicionales ${ }^{3} \mathrm{y}$, combinando el uso del sistema judicial y la acción directa, se involucraron activamente en el proceso de transformación política que estaba teniendo lugar ${ }^{4}$. En la base de su relación con el sistema español estaba una comprensión histórica de sus derechos (en particular sobre la tierra y su autogestión) que por lo mismo estaban sometidos a una constante negociación y redefinición ${ }^{5}$. La legislación sobre el trato de los esclavos fue otro cambio importante introducido en la región ${ }^{6}$. Aunque no se

1 Baber, 2005. Benton, 2002. Borah, 1983. Cutter, 1986. Ots y Capdequí, 1943: 286. Solórzano Pereyra, 1996, t. 1, lib. 2, cap. 29: 594 y ss. Stern, 1991.

2 Bennett, 2003; Blackburn, 2000. Bryant, 13/1 (Londres, 2004): 7-46. De la Fuente, 4 (Madrid, 2004): 7-22. Owensby, 85:1 (Durham, 2005): 39-80. Premo, 2005.

3 Censo del Gobierno de Popayán, Tovar, 1994: 319-335.

4 Echeverri, 11 (Bogotá, 2006): 343-376.

5 La noción de «pacto» ha sido muy útil para superar una noción más rígida del poder colonial y que representa el colonialismo como un mero ejercicio de dominación. Mi trabajo busca aportar evidencia para la redefinición del pacto como una relación flexible y dinámica, que cuestiona la construcción ahistórica del pacto, particularmente en la historiografía andina. Véase Platt, 1982.

6 Lucena Salmoral, 1996. 
puso en práctica después de la radical reacción de los esclavistas, esa legislación generó una percepción de cambio entre los africanos esclavizados. Como mecanismo de transformación en términos de la relación de sujeción, la Instrucción amplió sus expectativas frente a las posibilidades de emancipación o, por lo menos, mostró una creciente protección por parte de la Corona ${ }^{7}$.

A partir de esa compleja relación e interacción, se transformó el entendimiento y la defensa estratégica del discurso realista por parte de indios y esclavos en la provincia de Popayán durante los años de 1808 hasta 1820. Los eventos que tuvieron lugar en esa región tras la invasión napoleónica de la península resultaron en una significativa alianza entre, de un lado, indios y esclavos y, de otro, los representantes de los intereses de la monarquía. El argumento de este artículo es que en este contexto indios y esclavos buscaron beneficiarse de las circunstancias políticas y dar forma a sus derechos a través de su constitución en aliados de los realistas. A la vez que la historia política de ambos grupos en la región jugó un papel esencial en la naturaleza y forma de las relaciones entre éstos y las elites realistas, el proceso de negociación en sí mismo se convirtió en un precedente importante que definió las alianzas a lo largo de la década 1809-1820.

Si bien durante el período colonial ni indios ni esclavos tuvieron acceso a los rangos militares en Popayán, la principal innovación que advino con la crisis de la monarquía fue su incorporación (formal o informal) en los ejércitos. De enemigos potenciales los indígenas de Pasto y los esclavos en la provincia pasaron a convertirse en una importante fuerza de contención de la rebelión, con lo que pudieron exigir nuevos derechos y libertades. Aunque en algunos casos, como se verá a continuación, ni siquiera fue necesario haber ejercido una acción militar, en general para ambos colectivos la participación armada constituyó un medio de fortalecimiento sin precedentes. Las concesiones políticas del gobierno estuvieron ligadas a la importancia bélica y estratégica que ambos grupos adquirieron en el contexto de la guerra.

Así como los quiebres en la soberanía del rey propiciaron la aventurada elaboración institucional de nuevos mecanismos de gobierno a ambos lados del Atlántico, también condicionaron los términos locales de la política. Recientemente la historiografía de las independencias ha reconocido el importante papel que tuvo la Constitución de Cádiz en el establecimiento de lineamientos liberales en todo el mundo hispano. Sin embargo, pocos trabajos han reflexionado sobre las consecuencias del liberalismo español en las transfor-

7 Chávez, 2001. Echeverri, 11 (Bogotá, 2006): 343-376. Geggus, 1997: 1-50; Lucena Salmoral, 1994. 
maciones del realismo durante el mismo período. Esto claramente se debe a que éste hasta hoy ha sido el gran ausente de las investigaciones sobre los procesos de independencia. Por lo general, el realismo se ha asumido como un tema irrelevante para la comprensión de la formación de las repúblicas latinoamericanas, debido a las directrices teleológica y nacionalista presentes en la mayoría de los estudios sobre el período ${ }^{8}$. Desafiando tales presupuestos, este trabajo ofrece evidencias sobre la importancia histórica del realismo popular en tres niveles. Primero, se defiende que fue una alternativa política viable para los indios y los esclavos en Popayán durante la época de estudio, siendo el tributo y la lucha contra la esclavitud temas centrales en el proceso de negociación con el bando realista. Segundo, se demuestra cómo debido a la necesidad de las elites realistas de Popayán de atraer a ambos grupos a su causa se transformaron aspectos de la relación colonial. Y, tercero, se ilustra cómo el realismo indígena, en particular, estuvo determinado por la Constitución de Cádiz que inspiró a algunos indios en Pasto a buscar nuevos medios para alterar su condición social ${ }^{9}$.

En suma, el objetivo y resultado principal de este trabajo sobre la fase temprana de la guerra es aportar una imagen dinámica del realismo popular en Popayán que resalta las complejidades sociales y políticas de indios y esclavos realistas. En el último apartado del artículo se ofrece un breve análisis de los procesos relevantes que dieron continuidad o transformaron los derechos de ambos grupos durante la república temprana.

\section{LOS INDIOS Y LA NEGOCIACIÓN DE DERECHOS Y DEBERES: PASTO, 1809}

En la provincia de Popayán la guerra se insinuó cuando en Quito se organizó una junta de gobierno con el fin de «conservar intacta la religión cristiana, la obediencia al señor Fernando Séptimo y el bien y la felicidad de la patria» ${ }^{10}$. La Junta Suprema Gubernativa encabezada por Juan Pío de Montúfar y Larrea, segundo Marqués de Selva Alegre, propuso a Popayán que se acogiera en su plan. Lo que se planteó como una alianza política necesaria también reflejó las pretensiones de expansión territorial de Quito hacia la preciada zona minera de Barbacoas, al norte de Quito, eje histórico de la riqueza de Popayán. Desde el siglo XVIII tardío, la región de la sierra norcentral en el Reino de

\footnotetext{
8 Excepciones recientes son Gutiérrez, 2007. Méndez, 2005a.

9 Contribuciones al tema de la relación de los indios y la Constitución de Cádiz son Hünefeldt, 11-12 (Cusco, 1978): 33-57. Rodríguez, 14 (Quito, 1999): 3-52; 2006.

10 John Carter Brown Library (JCBL), Archivo Restrepo, Fondo I, vol. 25, f. 40.
} 
Quito estaba en decadencia y dependía de Popayán (también de Cuenca y Guayaquil hacia el sur ${ }^{11}$. En medio de la crisis imperial que sacudía todas las regiones hispánicas, el gobierno de Popayán reaccionó radicalmente contra la tendencia autonomista y expansionista de Quito. Ello fue seguido por la inmediata organización de un ejército de defensa por el Gobernador Miguel Tacón. Quito también formó un contingente militar que emprendió la marcha hacia el norte con el fin de invadir Popayán.

En vista de los planes de Quito de atacar entrando por Ibarra hacia la frontera sur de Popayán, y para cerrar el acceso a las minas de Barbacoas, el Gobernador Tacón reconoció que, como primer paso, se debía asegurar la lealtad de las comunidades indígenas del altiplano de los Pastos, ubicadas en una zona militar estratégica. Tacón escribió al Virrey en Bogotá acerca de la urgencia de establecer vínculos fuertes en Pasto porque las comunidades estaban expuestas «a los riesgos de seducción que pueden intentar los rebeldes» ${ }^{12}$. El acercamiento del gobernador a las comunidades se realizó a través del capitán de las milicias de Barbacoas, Gregorio Angulo, quien a fines de agosto de 1809 viajó a Pasto y ofreció a los gobernadores de los pueblos de indios una reducción en el pago del tributo a cambio de que éstos se presentaran para el servicio de la Corona. Angulo informó a Tacón que, como respuesta, «todos los mandones de los naturales de este distrito se me han presentado ya ratificando su buena disposición $\gg^{13}$. La participación de los indígenas fue decisiva en la victoria contra los ejércitos de Quito, que tuvo lugar en Funes en octubre del mismo año.

La reducción del pago del tributo en Pasto fue central para la consolidación de una alianza entre las autoridades indígenas y el capitán de las milicias. Esta estrategia de negociación puede ponerse en perspectiva a tres niveles. En primer lugar, durante el siglo XVIII, las comunidades en Pasto habían mantenido una posición fuerte y de éxito respecto a su conveniencia en el pago en especies (generalmente textiles) y no en moneda ${ }^{14}$. Es decir que, al plantear la reducción del tributo como un elemento de negociación, las autoridades realistas estaban apelando a la dimensión simbólica y económica que tenía el tributo como eje de la relación de la Corona con las comunidades. En segundo lugar, la oferta de Angulo fue significativa porque expresó muy bien la importancia de las dinámicas del poder monárquico entre los indígenas de la región. Con la condonación del tributo, las comunidades que se estaban movilizando militar-

11 Andrien, 2008: 17.

12 Archivo Histórico Nacional, Madrid (AHN), Consejos 21674, exp. 2, doc. 18, f. 2.

13 Ibidem, f. 8.

14 Williams, 1994: 136. 
mente recibían reconocimiento y prueba de la magnanimidad del gobierno ${ }^{15}$. $\mathrm{Y}$, en tercer lugar, la política militar borbónica había legislado sobre la importancia de ofrecer ciertos beneficios a las castas para integrarlas en las milicias imperiales que se estaban constituyendo desde comienzos del siglo XVIII. Aunque en el suroccidente de la Nueva Granada la propuesta (mejor recibida en otros lugares como Venezuela y Perú ${ }^{16}$ ) se rechazó, la coyuntura crítica de 1809 conllevó que esa política militar de integración de las castas se considerara desde otra perspectiva.

En el contexto de amenaza interimperial - la invasión francesa que se percibía como un riesgo muy real-y de polarización de las elites locales alrededor de las posiciones juntista y regentista, para Tacón era primordial asegurar la lealtad de los indios ${ }^{17}$. Anteriormente en Popayán éstos habían sido excluidos de las milicias y, además, existía el precedente de rebeliones indígenas en el distrito de Pasto en 1781 y 1800. Sin embargo, la situación ameritaba una reevaluación de esa política para afianzar los vínculos del gobierno con las comunidades. Una larga tradición historiográfica ha interpretado estas alianzas como reflejo de la tendencia «natural» de los indígenas al realismo, pero, como lo demuestra el temor de Tacón, la desconfianza del gobierno frente a los indios explica la desesperada necesidad de asegurar su colaboración con la causa real ${ }^{18}$. Las aventuradas decisiones que acompañaron la incorporación de los indios a las milicias en Popayán tuvieron importantes repercusiones en la relación de las comunidades con las elites locales. Como primera expresión de ese reajuste estuvo la paradójica respuesta de las autoridades de treinta pueblos de indios, un año después. Éstos dieron vuelta a la propuesta de negociación por parte de Tacón y Angulo y escribieron a Tacón en 1810:

«Desde que se supo la revolución de Quito [...] nos ofrecimos los indios a servir en esta justa causa con nuestras personas y vidas, sin interés alguno sino el de nuestra fidelidad y amor a nuestro desgraciado y amado Rey Don Fernando Séptimo. Posteriormente el Capitán Don Gregorio Angulo hizo publicar bando, prometiéndo1993.

15 Ver la discusión sobre la economía del favor en Cañeque, 2004: capítulo 5; y Hespanha,

16 Ricketts, 2008.

17 JCBL, Archivo Restrepo, Fondo I, vol. 25, f. 116; Arroyo y Valencia, 5 (Popayán, 1910): 29-34. En Popayán, el partido que apoyaba al gobierno de la Regencia en la península se denominó «taconcistas» porque estaban liderados por Miguel Tacón.

18 Véase Earle, 172 (Oxford, 2001): 125-145. Sobre la exclusión de las milicias véase Kuethe, 1978: 29. Las rebeliones de Pasto así como el contexto postinsurreccionario en los Andes del sur mantuvieron a las elites en una posición defensiva frente a los indios. Véase Earle, 73/1 (Durham, 1993): 99-124; Thomson, 2002; Walker, 1999; Williams, 10/3 (Albuquerque, 2001): 277-309. 
nos rebaja de una tercia parte del tributo a los que sirviésemos. Pudiéramos reclamar la gracia, pero lejos de hacerlo, considerando las necesidades y aflicciones que padece nuestro Rey y Señor Natural, por las traiciones y maldades de los franceses, cedemos en su Majestad la parte de tributo que se nos prometió condonar; y sintiendo nuestra pobreza, por no tener con qué socorrerlo, quisiéramos ser tan felices que pudiéramos redimir a nuestro amado soberano a costa de nuestras mismas vidas» ${ }^{19}$.

Tal proposición fue recibida con agrado por el gobernador, quien respondió:

«Hágaseles entender que admitiéndoseles, como se les admite, su liberalidad, deben estar firmemente persuadidos que en todo tiempo se tendrá presente para ser tratados con aquella consideración a que se han hecho acreedores como fieles vasallos del Señor Don Fernando Séptimo» ${ }^{20}$.

La intención de los caciques era, en primer lugar, garantizar un lugar privilegiado para sí mismos en el nuevo contexto político. Al continuar cobrando el tributo como una contribución para la guerra podían conservar sus beneficios económicos y políticos privados. Ello también les permitía controlar y reubicar de manera indirecta su posición jurisdiccional y de autoridad. La reducción del tributo a los indios de Pasto posiblemente desencadenó un proceso de movilidad interna en las comunidades frente al que los caciques pronto expresaron desconfianza, ya que no les interesaba tolerar una diferenciación social sin precedentes. El proceso de individualización y de fortalecimiento de aquellos involucrados y premiados por sus méritos en el servicio militar, así como la reducción del tributo a quienes servían en los ejércitos del rey, resultaba inconveniente para los caciques ${ }^{21}$.

Sin embargo, los indios de la comunidad estaban interesados en participar en las milicias, seguramente por esas mismas razones. La oportunidad de hacerlo continuó abierta durante los años de 1811-1812 cuando Quito nuevamente planteó una ofensiva contra Popayán, luego de haber organizado otra junta autonomista de gobierno. Para entonces hay evidencia de la intervención explícita del protector de indios, Francisco Martínez de Segovia, en la nego-

19 La representación la presentó el protector de naturales Francisco Martínez de Segovia a nombre de los pueblos de Jongovito, Obonuco, Catambuco, Botanilla, Gualmatán, Buesaqui1lo, Pejendino, Mocondino, Jamondino, Males, Canchala, Puerres, Aranda, Tescual, Pandiaco, Anganoy, Chapal, Genoy, Matituy, Mombuco, Matacunchuy, Tambo, Chachagüí, Buesaco, Monte, Yacanquer, Tangua, Funes y Sibundoy. Guerrero, 1912: 52-53. Énfasis añadido.

20 Guerrero, 1912: 54.

21 En la historiografía, esta carta no se ha analizado críticamente y se ha interpretado como una manifestación transparente del realismo indígena. Mi argumento busca contribuir al estudio de las dimensiones sociales conflictivas al interior de las comunidades reflejadas en este episodio. Véase, por ejemplo, Gutiérrez, 2007: 120. 
ciación del gobierno municipal de Pasto con los indígenas con el fin de garantizar su lealtad a cambio de una reducción en el cobro del tributo. Este episodio revela, primero, que aunque el gobierno local había evadido el decreto de abolición del tributo de las Cortes de Cádiz, este tema continuaba siendo fundamental en el proceso de negociación con los indios. La abolición del tributo estuvo estrechamente vinculada con los intereses de nacionalización que expresaron los diputados liberales en Cádiz desde temprano ${ }^{22}$. Pero era un proyecto difícil de llevar a cabo, no sólo porque el gobierno metropolitano estaba debilitado sino, también, porque en el contexto de la guerra el tributo consistía en uno de los mayores medios de recolección de fondos para los gobiernos ${ }^{23}$. A nivel local, sin embargo, que el protector estuviera apelando a una reducción del tributo en representación de los indios sugiere que las comunidades habían vuelto a poner esa condición en la mesa para asegurar su participación en las filas realistas. Y, asimismo, indica que la historia de las negociaciones con Tacón y Angulo en 1809 fue definitiva para instaurar un canal de negociación políticamente relevante en relación con las comunidades indígenas de Pasto que tuvo su eje en la reducción del tributo.

Una vez más en 1814 el nuevo protector, Juan Díaz Gallardo (llamado por su segundo apellido), tuvo que solicitar la intervención del rey para proteger los intereses de los indios que se encontraban defendiendo su causa. Según Gallardo, no se había puesto en efecto la prometida reducción del tributo, aun cuando en 1811 Tacón había decretado que el pago del tributo debía ser sólo de cuatro pesos. Aparte de reivindicar el decreto de Tacón, Gallardo también planteó una lista de puntos clave sobre los que basó la solicitud de los indios. Dijo, por ejemplo, que su situación era muy difícil dado el constante abuso que sufrían por parte de los miembros del ejército real. Gallardo denunció aquella injusticia e imploró que se remediase, considerando el constante apoyo y fidelidad de los indios hacia el rey. Igualmente, era necesario reconocer que éstos eran «las mulas de acarreo» en el transporte de todo lo necesario para la defensa y subsistencia de la tropa. El énfasis puesto por Gallardo en ello era importante porque, en la región de Pasto, los indios trabajaban regularmente como cargadores en el transporte de bienes desde Pasto hacia las minas de Barbacoas. Pero, en el contexto de la guerra, por cargar comida y artillería no se les estaba pagando siquiera el peso acostumbrado. Según el protector, aun

22 Chust, 11/2 (Berkeley, 1995): 183. De Armellada, 1979. Sobre la publicación de la Constitución de Cádiz en Pasto, véase Gutierrez, LXVIII/242 (Madrid, 2008): 207-224.

23 Como es conocido, aun dentro del régimen constitucional, el Presidente de Quito Toribio Montes evadió el decreto de abolición del tributo. Véase, Morelli, 2005, capítulo IV, especialmente pp. 170-171. 
en esas circunstancias los indios no se quejaban, y, por el contrario, servían acompañados de sus familias quienes les proveían el alimento necesario ${ }^{24}$. Al respecto, es también significativo que la participación de los indígenas en la guerra fuera descrita en términos de «servicio» $\mathrm{y}$, particularmente, que éste se realizase en compañía de las familias. Como es conocido, en la región andina la mita tuvo una importancia fundamental como medio de movilización de los indígenas al trabajo comunitario ${ }^{25}$. Hay una importante similitud entre la estructura comunitaria de apoyo en el servicio característica de la mita y la manera en que los indios de Pasto estaban contribuyendo al bando realista. Este tipo de servicio, por principio, implicaba una respuesta recíproca del rey en términos de otorgar ciertos derechos/privilegios a las comunidades indígenas. De ahí que la petición de Gallardo remarcase la particular intersección entre el establecimiento coyuntural de estructuras comunitarias que movilizaron recursos económicos y sociales para servir al rey.

El reconocimiento de la importancia que el servicio militar adquirió entre los indios de Pasto no debe llevar a suponer que, con su servicio, estaban reproduciendo un tipo de pacto ahistórico con el rey. Su participación y la manera en que se situaron como aliados políticos y militares de los realistas fueron profundamente estratégicas y, al propiciarles grandes beneficios comunitarios, les pusieron en una posición privilegiada entre los realistas de la Nueva Granada ${ }^{26}$.

Aun cuando el memorial de Gallardo hablaba de los indios dentro de un marco jurídico tradicional, como rústicos y miserables, su fin era resaltar la participación de las comunidades en la guerra a través del servicio militar (como cargueros, dotados de provisiones y como soldados) para sustentar la petición de reducción del tributo. Es evidente que Gallardo estaba representando los intereses de los indios del común que veían como excesivo el cobro del tributo ante su apoyo en la guerra. Es decir, se les estaba exigiendo demasiado $\mathrm{y}$, por ello, solicitaban una reducción del tributo a cambio del servicio militar. Pero la movilización del protector a favor de los indios del común claramente contradecía los intereses de los caciques, quienes en 1810 habían declarado que las comunidades cederían al monarca el tributo que originalmente Angulo y Tacón les condonaron. Mientras que los caciques estaban defendiendo su posición y obligando a los indios a cumplir con ambas obligaciones, los indios del común se aliaron con Gallardo para buscar que se reconocieran sus intereses a nivel del cabildo y de las autoridades virreinales. El resultado de aquella

\footnotetext{
24 Archivo Nacional del Ecuador, Quito (ANE), Popayán 342, 13-XII-1814, f. 4v.

25 Véase Stern, 1991: 80-96.

26 Platt, 1982; Saether, 2005a.
} 
petición sólo tuvo respuesta cuando Fernando VII retornó al trono. El 15 de mayo de 1817, el rey decretó una reducción perpetua del tributo a los indios de Pasto y declaró su satisfacción con sus servicios ejemplares y leales ${ }^{27}$. También ordenó que los caciques de aquellos pueblos tuvieran el privilegio de usar una medalla de plata con el busto del rey tallado y escrito «a los caciques de Pasto por su fidelidad, Fernando VII $\rangle^{28}$.

Sin embargo, la alianza entre los indios y el protector fue causa de varios conflictos que involucraron a las comunidades del distrito de Pasto. En el mismo año 1817 , los indios protestaron contra la autoridad de los curas y contra los servicios de pongo o platucama que éstos les exigían. Gallardo también jugó un papel importante en este proceso pues volvió y apoyó a los primeros con el fin de transformar el servicio personal que tradicionalmente prestaban a los curas $^{29}$. Y, por esa razón, después de una intensa ola de protestas de caciques y curas en contra de Gallardo, la Audiencia de Quito ordenó su remoción del cargo de protector y su reemplazo por Ramón Medina, un capitán de milicias del ejército realista en Pasto $^{30}$. Ante ello, Gallardo trató de defenderse ante la Audiencia. En 1818 declaró como injusta su remoción e insistió en la importancia que había tenido su gestión en la movilización de los indios a favor del rey, un punto que seguramente se recibiría bien entre los oidores de Quito. Además, recordó que él había acompañado a los indios a pelear en varias ocasiones y señaló que éstos le querían porque les había tratado como a sus hijos $^{31}$. Estos argumentos revelan los niveles de politización del oficio de protector en Pasto durante la guerra. Primero, había jugado un papel central en comprometer a los indios con la causa realista. Y, segundo, en esa posición de autoridad Gallardo también había adquirido responsabilidades con ellos, como eran la reducción del tributo y su defensa ante los abusos de los curas. Como ese último componente de la relación entre los indios y Gallardo causó controversia por no convenir a los caciques, el protector general de indios en Quito

27 ANE Popayán 350, 9-I-1819, f. 52v.

28 Ibidem. Este tipo de reconocimiento a los caciques también se usó en Santa Marta y en Venezuela. Sobre el premio a los caciques de Mamatoco (Santa Marta), veáse AGI Santafe 632, Cuba 749 y Saether (Cambridge, 2005b): 73. Sobre las medallas que en 1819 Pablo Morillo otorgó a los caciques de Pilar, Caigua, San Miguel, San Francisco, Clarines y Piritu en Venezuela, véase Real Academia de Historia, Madrid (RAH), Colección Morillo 9.7664, fs. $287-287 \mathrm{v}$. tificar.

29 ANE Popayán 350, 9-I-1819, f. 81v. El significado de platucama no se ha podido iden-

30 Ibidem, f. 31.

31 Ibidem, f. 77v. Por ejemplo, Gallardo acompañó a los indios de Catambuco durante una confrontación militar en 1812. 
justificó la remoción de Gallardo diciendo que había recibido numerosas quejas en su contra de éstos y de los curas, quienes explícitamente imploraban su reemplazo por Medina. Es decir, la Audiencia también rechazó a Gallardo por su alianza con los indios del común. El contexto de este cambio es importante, porque a partir de 1814 con el regreso de Fernando VII al trono la política de gobierno comenzó a dar un giro hacia una línea absolutista similar a la que existía antes de 1808. La visión de cambio que se había institucionalizado entre 1810 y 1812 con las cortes liberales comenzó a ser desmantelada bajo las órdenes del monarca y en Pasto esto tuvo repercusiones: la crisis en la protectoría de naturales.

Los conflictos de los curas con los indios de la ciudad de Pasto resultaron de las críticas que estos últimos plantearon frente a sus deberes con los religiosos. Los caciques de Obonuco y Botanilla, así como las autoridades de Jongovito, dijeron que los indios en sus pueblos se habían declarado en contra del cura y que se negaban a pagar por sus servicios de misa, entierros y matrimonios, llegando algunos a dejar de atender a la primera ${ }^{32}$. Para los caciques, la situación era resultado de la relación de los indios con el protector, quien había promovido discordia, división y rebelión entre sus pueblos. Asimismo, éstos dijeron que en esas circunstancias en que los indios habían perdido toda la debida veneración a los curas, «rodeados de unos indios sublevados y sin respeto», estaban en riesgo sus propias vidas y su autoridad estaba en duda ${ }^{33}$. Tales quejas sugieren que, entre los pueblos que se habían declarado realistas, Gallardo había promovido los intereses de los indios que estaban buscando cambios en sus condiciones de sujeción frente a caciques y curas. En parte, tal desafío se apoyó en las transformaciones liberales institucionalizadas durante el período de gobierno de las Cortes de Cádiz. Las leyes que promovió la Constitución de 1812 incluían cambios en el trato que curas y otras autoridades daban a los indios. Gallardo claramente fue un agente en la difusión de tales preceptos entre ellos, quienes intentaron llevarlos a sus últimas consecuencias ${ }^{34}$.

La elite indígena se vio amenazada por los cambios que buscaban algunos indios en los pueblos del distrito de Pasto y trató de resolver el problema a tra-

32 Ibidem, f. $25 \mathrm{v}$.

33 Ibidem, f. 26.

34 El principal aporte indigenista lo realizó el diputado peruano Dionisio Inca Yupanqui. Véase Archivo del Congreso de los Diputados, Madrid (ACD), Sección General, Legajo 7 n. 27 y Legajo 6 n. 89. Los debates sobre el tema en Cádiz se tratan en De Armellada, 1979: 13-14. Pascual Temaran, un indio del pueblo de Catambuco, dijo que Gallardo les había prometido aplicar un mandato real que reducía el servicio a los curas. ANE Popayán 350, 9-I-1819, f. 130. 
vés del ataque a Gallardo y la petición de su remoción. Una vez que el contexto político de la monarquía cambió y se oficializó la visión absolutista del rey, los caciques y curas pudieron reclamar el apoyo de la Audiencia para rectificar la situación. En ese momento los cambios que algunos indios requerían con el apoyo de Gallardo fueron frenados por la alianza de la Audiencia, los curas y los caciques a través del nombramiento de un protector que se consideró que realmente conservaría el orden. Esto se vio reflejado en la Cédula Real del 29 de abril de 1817. Ésta respondía a las quejas de los curas ante la insubordinación de los indios frente a las autoridades religiosas y volvía a autorizarles a castigarles, criticando el «desorden causado en los pueblos de indios» a causa de la Constitución de Cádiz y otras resoluciones de las Cortes. Es decir, las numerosas quejas de curas y caciques contra Gallardo y la afirmación de los gobernadores de Obonuco, Calambuco y Jongovito sobre la necesidad de una «reconquista de los pueblos» evidenciaban que los cambios introducidos durante el período liberal de gobierno se habían percibido como una amenaza a su poder y posición. A la vez, el uso del término «reconquista» por parte de los caciques no sólo expresaba simpatía por el proyecto de reconquista liderado por Pablo Morillo desde 1814 y encabezado por Aymerich y Sámano en el suroccidente, sino también apelaba a la necesidad de ejercer fuerza sobre los indios en revolución.

Resulta paradójico que estas quejas hayan surgido precisamente en los pueblos que se caracterizaban por su filiación realista. Ello, sin embargo, obliga a reconsiderar la imagen del realismo como puramente arcaizante. En realidad, la evidencia analizada aquí demuestra que los indios realistas de Pasto se acomodaron a los cambios de la política metropolitana y también aprovecharon las oportunidades que a nivel local surgieron con el contexto de militarización. Por ello estuvieron dispuestos a negociar con el gobernador Tacón y con el capitán de milicias Gregorio Angulo en 1809. El desarrollo de la guerra, así como la historia particular de esas alianzas, dieron lugar a diferenciaciones internas en las comunidades y a serios conflictos entre los indios del común, los caciques y las autoridades religiosas. Tales conflictos ejemplifican la complejidad del realismo indígena. Por un lado, con el apoyo dado a las autoridades realistas en la segunda parte de la década (1815-1820) los caciques fortalecieron su estatus dentro de la comunidad. Por otro, ese apoyo no necesariamente implicaba una aceptación de los dos pilares de gobierno - «Dios y el Rey». Como ilustra el caso de algunos indios del común en el distrito de Pasto, éstos se asumieron como aliados del rey para intentar transformar la naturaleza del poder y el gobierno coloniales en relación con las comunidades indígenas ${ }^{35}$.

35 Sobre los pilares del gobierno hispano, véase Cañeque, 2004. 


\section{LIBERTAD EN MEDIO DE LA GUERRA}

A comienzos del siglo XIX, cuando estallaron los primeros conflictos entre las ciudades neogranadinas suroccidentales de Quito y Popayán, las cuadrillas que habitaban el territorio Pacífico, trabajando en las minas y haciendas, intentaron con rapidez colocarse en una posición de ventaja en el nuevo panorama político imperial y regional. Mientras en 1811 las elites esclavistas de Cali y Popayán, en su mayoría, enfrentaban al gobernador español Miguel Tacón, los esclavos en las minas de Yurumanguí y San Juan anunciaron a sus dueños que se rebelaban contra ellos con el pretexto de estar en contra de su insurrección. Los de Yurumanguí decían que:

\footnotetext{
«Ellos, que en tanto eran esclavos en cuanto sus amos habían sido vasallos del Rey, que los amparaba y dispensaba su real protección cuando la imploraban contra la sevicia y crueldad con que los trataban, no debían continuar en su dominio y servidumbre sino gozar de la misma libertad que los vasallos fieles con subordinación únicamente a su majestad y a sus ministros, bajo cuyo dominio y autoridad protestaban permanecer» ${ }^{36}$.
}

Los esclavos de San Juan, según informó su dueño, Gerónimo Torres (sic), estaban buscando conseguir la libertad aún antes de que comenzara el enfrentamiento entre las elites locales. En 1810 se habían levantado diciendo que «había venido a las Américas una reina negra trayendo la libertad para los esclavos que trataban los amos de ocultarla con cuyo [motivo] habían comenzado a celebrar juntas nocturnas y tomar medidas para sacudir la obediencia». Poco tiempo después, a principios de enero de 1811, «mandaron a prevenir no contáse[n] sus amos con los esclavos ni la mina porque ésta era suya y ellos libres ${ }^{37}{ }^{37}$. Los esclavos afirmaron que el gobernador Tacón les había otorgado la libertad mediante un decreto. Según Torres, el argumento de los esclavos era fruto de un rumor llevado a la mina de San Juan por un par de desertores del ejército realista.

El empleo de los rumores de libertad en esta mina sugiere varias cuestiones importantes. Primero, ambos rumores - el de la negra que llegó a América emancipando a los esclavos y el del decreto de Tacón liberando a los esclavos a cambio de su lealtad - comparten un elemento típico y común de los rumores de libertad que circularon en esa época por el mundo Atlántico: los esclavos culpaban a los amos de no reconocer un decreto que hacía justicia y les otorgaba la libertad ${ }^{38}$. Segundo, los esclavos estratégicamente vin-

\footnotetext{
36 Archivo General de Indias (AGI) Quito 386, documento sin numeración.

37 Archivo Central del Cauca, Popayán (ACC), Independencia CIII 2g 6596, f. 1v.

38 Geggus, 1997; Childs, 2006: 160.
} 
culaban sus acciones a tales tipos de decretos buscando legitimar las rebeliones. Tercero, el hecho de que antes de la guerra y en su inicio los esclavos de San Juan apelaran a decretos de manumisión vinculados con símbolos de autoridad monárquica (la reina negra y el gobernador de Popayán) revela que para éstos la libertad no estaba necesariamente por fuera del universo monárquico o de la cultura política monárquica. Esto, precisamente, permite cuestionar la idea de la asociación natural entre las rebeliones de esclavos y el anticolonialismo. Por mucho tiempo se ha asumido que los esclavos sólo buscaban conquistar la libertad por medios como la fuga y la rebelión, con el fin último de negar o escapar del mundo esclavista. Sin embargo, el ejemplo de los esclavos que profesaron ser realistas en Popayán ayuda a reflexionar sobre el nivel de manipulación estratégica que grupos de esclavizados daban a los contextos políticos y judiciales en los cuales se encon$\operatorname{traban}^{39}$.

El argumento de los esclavos de Yurumanguí y el rumor contemporáneo que circulaba en San Juan acerca de la liberación de los esclavos por parte del gobernador sugieren que la intención de los esclavos era sustentar su búsqueda de libertad en el contexto monárquico y no negarlo recurriendo a una justificación por fuera de éste. Apelaron abiertamente a la ilegalidad de la rebelión de sus amos, sentando como punto de partida su propia comprensión de la relación esclavista, en la que sólo era legítimo que se les mantuviera en ella mientras el rey estuviese a la cabeza de la misma. Una vez rota esa jerarquía a causa de una rebelión anticolonial de sus amos, los esclavos no tolerarían permanecer bajo su yugo. Es decir, su definición de la servidumbre dependía enteramente del principio de legalidad. Asimismo, la manera en que los esclavos del Pacífico neogranadino afirmaron los principios de la cultura política monárquica tuvo que ver con las oportunidades que se presentaron y con el desarrollo particular de la guerra en Popayán. Esto es, no es necesario hacer una generalización sobre la relación de los esclavos con la alternativa monárquica, ya que, por ejemplo, en el Caribe hubo varios casos de esclavos que acogieron el republicanismo en su lucha por conseguir la libertad y asegurar su emancipación ${ }^{40}$. Pero en Popayán, la alianza entre los esclavos y los realistas durante la década de 1809-1819 se fortaleció por el hecho de que sus dueños, además de

\footnotetext{
39 Véase Childs, 2006, como ejemplo para el caso cubano.

40 Por ejemplo, durante la revolución francesa, en la isla de Guadalupe en 1793 se produjo una gran rebelión de esclavos. Cuando se intentó pacificarles argumentaron que se habían levantado a favor de la república y en contra de sus amos que se mantenían realistas. Véase, Dubois, 2006: 237. Sobre la integración de esclavos a los bandos independentistas en otras regiones sudamericanas, véase Blanchard, 2008.
} 
apoyar a los juntistas de Bogotá y Quito, no tenían intereses de negociar con ellos ofreciéndoles la libertad ${ }^{41}$.

Los esclavos también se beneficiaron de estar en un lugar aislado, como lo era el litoral Pacífico. Durante los años de la guerra, los dueños de las minas se ausentaron por largos períodos de tiempo para mantenerse al frente de los ejércitos rebeldes. Las cuadrillas de esclavos aprovecharon ese nuevo grado de autonomía y libertad que la situación les proporcionó y decidieron negociar con Tacón y los demás realistas que buscaban mantener a los esclavos de su lado aunque sin ejercer un control directo. Después de todo, los realistas también tenían que mantenerse móviles para poder defenderse de los ataques militares de las fuerzas insurgentes. Es decir, entre 1809 y 1814 los intereses de las elites realistas y de los esclavos se combinaron. Los primeros lograron establecer un control indirecto de la región minera a través de los esclavos quienes afirmaron que permanecerían fieles a la Corona mientras se les asegurara su autonomía. Por supuesto, el intercambio que se estableció no era transparente y tampoco directo. Los esclavos demandaban la libertad, pero Tacón y las demás autoridades coloniales en ningún momento tuvieron planes de abolir la esclavitud o de emancipar a los esclavos. Las negociaciones con ellos se llevaron a cabo de manera informal y no hubo un decreto que anunciara esta oferta ${ }^{42}$. La ausencia de tal política se intentó confirmar por medio de un cuestionario que elaboró el mismo Tacón para defenderse de las acusaciones que se le hacían al respecto y al que respondieron veinte esclavos provenientes de las haciendas de Popayán. Los esclavos que trabajaban en las haciendas estaban en una situación muy distinta de aquellos que vivían en las minas, con menor capacidad para rebelarse. Por lo mismo, su opción de unirse al ejército realista reflejaba una acción estratégica de acuerdo a sus posibilidades. Estos veinte esclavos dijeron haber tenido noticias de los planes de sus amos de rebelarse contra el gobierno de Tacón. Añadieron que por temor a ser obligados a colaborar con el proyecto insurgente se habían escapado para encontrarse con Tacón y su ejército realista. El testi-

41 Véase el trabajo de Brown, 10 (Medellín, 2004): 109-125, sobre los antagonismos de las elites autonomistas en Cali y los movimientos de negros a favor de la independencia.

42 Es importante esta aclaración, dado que se ha supuesto en la historiografía colombiana que Tacón ofreció la libertad a los esclavos. Sin embargo, tras una búsqueda exhaustiva del supuesto decreto y el análisis de las fuentes encontradas, es más plausible argumentar que la liberación de los esclavos se manejó a la vez como rumores por ser un tema de contención entre los realistas y los revolucionarios y que las negociaciones entre realistas y esclavos se dieron informalmente. ACC Independencia CIII 2g 6597; AGI Quito 386; y «Oficio del gobernador de Popayán, don Miguel Tacón, al Virrey don Benito Pérez», Documentos Importantes de Nueva Granada, Colombia y Venezuela, 1969: 75. 
monio también buscaba aclarar la naturaleza de aquella acción. Los esclavos debían probar que no se trataba de un acto rebelde en contra de sus amos, sino que la fuga se había realizado con el fin de defender a la ciudad sin la intención de actuar en su contra ${ }^{43}$. Y, aun así, se observaba una intención en los esclavos de confrontar a sus amos en la lucha armada, posibilidad que se haría real una vez que éstos se alistaran en el ejército. Más aún, con su participación en las milicias realistas estarían bajo la protección del gobierno y, a la vez, en posición legítima para enfrentar a sus antiguos amos.

Mientras los esclavos se aliaban y defendían a la Corona que históricamente apoyaba a la esclavitud, el gobierno realista movilizó a los esclavos contra sus amos. Y, desde su punto de vista, este proceso de alianza con el ejército realista resultaba aparentemente paradójico, porque, si bien los esclavos (tanto en la ciudad como en las minas) estaban buscando la libertad, asumían el compromiso de mantenerse sujetos a la soberanía del rey. Éste era el punto preciso que aseguraba a las elites el apoyo que los esclavos daban a la causa realista. Ello no era contrario al hecho de que el manejo de las oportunidades de negociación por parte de los esclavos en la provincia de Popayán sugería que éstos medían sus oportunidades cuidadosamente, como mostraba el proceso que se abrió en 1816 a favor de los esclavos de la mina de San Juan cuando Camilo Torres, el capitán de la mina, presentó una petición en su nombre y de sus otros veintitrés «compañeros» en la misma mina. Torres solicitó que se reconocieran los servicios de éstos a favor de «nuestro soberano» y se les otorgara la libertad. Su argumento era que habían estado guardando el territorio de la entrada de los insurgentes y que al menos en dos ocasiones les habían hecho frente. Según los testimonio de Torres y otros líderes militares, los esclavos habían permanecido bajo las órdenes de las autoridades realistas (jueces y curas) en la región, rechazando los esfuerzos de los insurgentes por ganarlos para su causa. Su esfuerzo bélico había sido muy meritorio teniendo en cuenta que no tenían suficiente número o $\operatorname{armas}^{44}$.

Aunque no está clara la resolución de este caso, es importante reflexionar sobre el avance que realizaron estos esclavos al aparecer frente a la justicia para solicitar su libertad como premio por permanecer fieles al rey. Este acto reflejaba la importancia que los esclavos del Pacífico neogranadino le daban a las instancias judiciales como un medio para adquirir sus derechos. Esto resultaba aún más evidente si se atendía a la denuncia paralela que hizo el dueño de la mina, Gerónimo Torres, quien afirmó que la cuadrilla se había

43 AGI Quito 386 (doc. sin numeración).

44 ACC Independencia CIII $2 \mathrm{~g}$ 6598, f. 1. 
convertido en un palenque durante los años de la guerra (1811-15). Según Torres:

«en marzo del mismo año [1811] ... se afianzaron más en su libertinaje, que alarmaron con su conducta muchas cuadrillas de la costa y que abrieron un asilo a todos los esclavos fugitivos desde aquel tiempo se pusieron en una absoluta indiferencia, se gobernaron por sí mismos y trabajaron sólo para su comodidad y provecho» ${ }^{45}$.

Esto sugiere que los esclavos de la mina de San Juan llevaban varios años viviendo en un estado de autonomía casi completo. Sin embargo, parecería que tenían una relación con las autoridades realistas quienes legitimaban su situación a cambio de que éstos defendieran el territorio de las intrusiones de los insurgentes. El abogado que acogió la representación de Camilo Torres en nombre de la cuadrilla tuvo en cuenta el precedente de la liberación del mulato Joaquín quien el año 1811 había recibido su libertad por una acción valiente que realizó en combate. Como se mencionó antes, no hubo un decreto oficial de libertad a los esclavos que se unieran a las milicias realistas. Sin embargo, el precedente legal del mulato Joaquín servía para motivar a otros esclavos a permanecer leales al rey así como para defender sus peticiones de libertad ante la corte. El abogado defensor también mencionó que, al regresar al trono, Fernando VII había declarado su deseo de premiar el «mérito y la virtud» de sus vasallos leales ${ }^{46}$. Con ello, el caso de los esclavos de San Juan se ubicaba no solamente en el contexto local, que les favorecía, sino también en el contexto imperial que tenía en ese momento gran relevancia para las peticiones de los esclavos. Es más, éstos posiblemente eligieron presentar su petición en ese momento dado el contexto positivo que se les planteó a partir del comienzo de la reconquista en 1815. Así como durante ésta los agentes de Fernando VII emprendieron una campaña sistemática de castigo contra los insurgentes, en los mismos años se reconoció la fidelidad de los realistas.

La petición de los esclavos de la mina de San Juan revela la importancia que tuvo para los de la provincia de Popayán encontrar una sanción legal para su libertad. Habían gozado de ella durante su permanencia autónoma durante la ausencia de sus dueños de las minas, pero necesitaban que el sistema judicial colonial la garantizase, sobre todo una vez que los realistas parecían ser los vencedores en la guerra. Nuevamente aquí se revelaba la relevancia de las estructuras jurídicas y los contextos políticos locales e imperiales para la acción política de los esclavos. Éstos estuvieron dispuestos a negociar sus derechos a través de su participación formal e informal en las milicias realistas,

45 ACC, Independencia CIII 2g 6596, f. 1v.

46 Ibidem. f. 6. 
siendo a través de las acciones legales cómo exigieron que se reconociera su derecho a recibir la libertad.

\section{CONCLUSIÓN: DERECHOS Y DEBERES INDIANOS Y LA BÚSQUEDA DE LA LIBERTAD PARA LOS ESCLAVOS EN LA REPÚBLICA TEMPRANA}

Este estudio de la movilización militar de indios y esclavos a favor de la Corona en el suroccidente de la Nueva Granada sugiere que se debe desencasillar el realismo de la categoría «conservador». En realidad, como se ha mostrado aquí, las comunidades de indios y de esclavos se apropiaron de las posibilidades que el realismo les otorgaba para intentar cambiar sustancialmente su posición y los términos de su relación dentro de la monarquía hispánica. Se basaron tanto en sus derechos históricos, como en las nuevas oportunidades particulares que la situación de inestabilidad y cambio generó. El realismo no implicaba mantenerse dentro de un esquema tradicional, estático o ahistórico, ya que así como el pacto con el rey y las autoridades coloniales había estado siempre en constante negociación, durante el período independentista se incorporaron importantes cambios surgidos a nivel local e imperial que ayudaron a redefinir los términos de la relación.

Después de la independencia, en 1821 el Congreso de Cúcuta eligió a Simón Bolívar presidente de la naciente República de Colombia. El Congreso planteó como meta nacional la incorporación de los esclavos negros y de los indios a la misma como ciudadanos. Aunque la igualdad era la máxima promesa, la estructura legal que se estableció en la Constitución para facilitar el proceso de integración de las castas coloniales reprodujo la dualidad y las diferencias previas. Esto tuvo consecuencias en la acción política ejercida por ambos grupos, teniendo cada uno reacciones e intereses diferentes a la hora de enfrentar las contradicciones y oportunidades que los cambios en el sistema político les ofrecían. Durante los primeros años de la vida republicana tanto esclavos como indios estuvieron dispuestos a incorporarse a través de las categorías políticas en desarrollo. Aun cuando nuevamente recurrieron a la acción directa para manifestar sus demandas y ejercer su capacidad política, ambos grupos buscaron integrarse a la vida nacional legal y expandir sus derechos. Nuevamente en este período se presentaron las oportunidades de participar en las milicias, lo cual se convirtió en un importante canal de negociación con los líderes republicanos. En esta conclusión no se pretende agotar el tema de los cambios particulares que tuvieron lugar en el período republicano temprano, sino sólo ilustrar algunos de los ejes relevantes de la relación de ambos grupos con el nuevo Estado. 
En el caso de Pasto, una vez que las elites de la provincia negociaron con Simón Bolívar en 1820, los indios protagonizaron una importante rebelión. La insurrección popular realista resistió la capitulación firmada entre el ejército español y las elites criollas locales, ocasionando durante los años de 1820 a 1825 graves problemas para el ejército grancolombiano en su marcha al sur a fin de establecer una confederación suramericana independiente. La rebelión la lideró Benito Boves, un coronel español que, tras la capitulación de Quito, organizó un ejército realista de resistencia en Pasto. Allí, a pesar de la campaña del obispo a favor de la capitulación, los pastusos se rebelaron en contra de la decisión de rendirse ante los invasores del norte ${ }^{47}$. Un elemento importante de la rebelión popular en esta etapa de confrontación contra la República colombiana fue el liderazgo de Agustín Agualongo, un hombre al que generalmente se ha clasificado como indio ${ }^{48}$. Agualongo había estado en el ejército realista desde 1811 y ejerció su mando hasta que, perseguido por los republicanos, murió en Barbacoas en julio de 1824. Había sido el capitán de las milicias realistas al lado de Estanislao Merchancano, un criollo de Pasto. Cuando comenzó la sublevación de Boves, en octubre de 1822 los tres cabecillas reconfiguraron las milicias y el gobierno realistas y obligaron a pagar altos impuestos a los «traidores» que habían negociado con Bolívar poco antes.

Durante la rebelión, entre 1822 y 1824 Agualongo y Merchancano nombraron a Ramón Medina como protector de naturales. Medina, como se señaló arriba, había apoyado la contrarrevolución absolutista de las autoridades indígenas, particularmente las de Obonuco, Botanilla y Jongovito. Medina también nombró gobernadores indígenas de su confianza, como en el caso de Andrés Pianda en Anganoy, causando gran controversia entre los indios. Interesa señalar que Boves, Agualongo, Merchancano y Medina movilizaron a las comunidades indígenas en 1823 contra el gobierno republicano precisamente a través de Andrés Pianda. Esto sugiere que el realismo entre las comunidades

47 Para poder calmar la rebelión, Bolívar tuvo que viajar a Pasto con la mayor parte de las tropas colombianas. Además cambió de la política suave delineada en la capitulación a otra más severa de pacificación contra los que ahora llamaba «insurgentes». Aquellos que tenían posesiones las perdieron y el castigo para la gente de la plebe fue obligarlos a unirse al ejército republicano en su campaña hacia el sur.

48 Agualongo es una figura mítica en la historia de Pasto y del realismo en la región. Sería importante aclarar si se trataba de un indio o no, pero en la historiografía este problema se ha convertido en un medio para racializar la memoria del realismo. Se ha interpretado como un problema de raza mientras que el proyecto político de Agualongo no se ha estudiado. Hemos heredado las caracterizaciones de Agualongo de Restrepo como un fanático e idólatra de Fernando VII. Restrepo, 1854: 256. Ortíz, 1958: 15-27. Bastidas, 1979: 113. Guerrero, 1994: 141. Miramón, 27/313-314 (Bogotá, 1940): 968-985. 
indígenas de Pasto en la década de 1820 estuvo dominado por las autoridades étnicas que se fortalecieron durante la reconquista. Así como habían reaccionado contra la progresiva diferenciación interna de las comunidades durante el período liberal en la monarquía, estas autoridades buscaban conservar un estatus privilegiado en el nuevo contexto político. Entre esos intereses estaba el de mantener el derecho de los indios a sus tierras comunitarias, un aspecto de la organización social y legal hispánica que la República de Colombia estaba atacando directamente ${ }^{49}$. En el Decreto del 20 de mayo de 1820 - más tarde convertido en el artículo 3 de la Ley del 11 de octubre de 1821-, Bolívar anunció el plan de dividir las tierras comunales y otorgarle a los indios propiedades individuales y privadas. Ambas leyes eran consistentes con el proyecto republicano de convertir a los indígenas en ciudadanos iguales a los demás colombianos. Asimismo, después de la independencia se abolieron los cacicazgos. Como parte de la política republicana de incorporar a los indígenas a la nación el gobierno dejó de reconocer a las autoridades hereditarias en las comunidades. Estas medidas fueron un ataque del gobierno bolivariano contra el poder de los caciques que se opusieron al proyecto republicano, sobre todo en la región suroccidental de Colombia. Sin embargo, esta intención legal de los reformistas no fue necesariamente efectiva ni transformó la manera en que los indígenas percibieron a sus autoridades. Durante el siglo XIX sus líderes militares y políticos operaron como «caciques de facto». Y el poder de los caciques se derivó, sobre todo, de su participación en las guerras civiles ${ }^{50}$. Así que la relevancia de las estrategias militares que se comenzaron a desarrollar durante las guerras de independencia continuó siendo importante después de la consolidación del Estado republicano ${ }^{51}$.

Por otra parte, la posición del Estado republicano temprano frente a la abolición de la esclavitud fue ambigua. En el suroccidente, desde comienzos de la guerra los insurgentes habían rechazado la negociación abierta con los sectores populares. Esto fortaleció la relación positiva que se había desarrollado entre los esclavos y el realismo. Sin embargo, para el proyecto republicano al mando de Bolívar movilizar a los esclavos se convirtió en una opción que se

49 Véase, «Ley sobre la extinción de los tributos indígenas, distribución de sus resguardos y exenciones que se les conceden», Congreso de Cúcuta de 1821. Constitución y Leyes, 1971: 248-252; Friede, 1972: 106. Esta ley fue una continuación del proyecto borbónico de división de tierras indígenas, exitoso sobre todo en la región central alrededor de Bogotá.

50 Rappaport, 1998: 96, 98.

51 La relevancia de las estrategias militares como medio para lograr la inclusión en el estado republicano ha sido estudiada en: Irurozqui, 2005: 285-320; Irurozqui, 2003:115-152. Macías, 2003: 137-152. Méndez, 2005:125-154. Peralta, 1999: 231-252. 
hizo cada vez más necesaria con el desarrollo de la guerra. Las cuadrillas del Pacífico se dieron cuenta de que con el retorno del rey la posición de los realistas se había vuelto menos flexible y reconocieron que una posible vía alternativa para asegurar su libertad era la participación militar activa a favor de la república. Sin embargo, el proyecto republicano se mostraba incapaz de llevar a cabo la abolición de la esclavitud y la integración de los afrodescendientes a la nación. Aun cuando los insurgentes usaban el símbolo de la esclavitud para representar el colonialismo y definían su lucha en contra de las cadenas de la tiranía y por la liberación, no pretendían negociar los términos de la institución de la esclavitud. Una vez que Bolívar atravesó los llanos venezolanos como líder de la lucha andina por la emancipación, organizó el Primer Congreso Constituyente en Angostura en el año 1819. Ahí fue donde Bolívar intentó poner en práctica sus previas promesas de liberación y emancipación, resultado de su denuncia del colonialismo español respecto a la inmoralidad del tráfico y la explotación de africanos ${ }^{52}$. Pero hacer de la abolición una meta republicana fundamental no fue fácil. Las tensiones entre los discursos de libertad cívica y política promulgados por Bolívar y los intereses de la base social de su proyecto independentista (criollos poderosos que dependían de la economía esclavista) se hicieron evidentes en la respuesta que su propuesta recibió en el Congreso. Se prohibió el tráfico de esclavos pero la abolición no se decretó. El resultado fue la Ley del 21 de julio de 1821, que se inspiró en leyes con las cuales se había experimentado anteriormente ${ }^{53}$. Bolívar también intentó integrar a los esclavos en el ejército de liberación. La necesidad de soldados en 1820 lo llevó a solicitar cinco mil esclavos para su reclutamiento, pero esta medida se distinguió claramente de una emancipación general de los esclavos. Parte del interés de Bolívar era prevenir que en las postrimerías de la guerra el número de afrodescendientes fuera mayor al de blancos.

Después de la independencia, las dinámicas raciales de la República vieron la marca del legado ambivalente de los años anteriores. Aunque la abolición se legisló de manera gradual para que los derechos de propiedad de los esclavistas se vieran protegidos, los esclavos socavaron los mecanismos dispuestos por esa institución hasta un nivel en que se vio prácticamente extinguida. En

52 Después de 1815, Bolívar instauró medidas que respondieron a su alianza con el presidente haitiano Alexander Pétion. En junio de 1816 declaró libres a los esclavos que apoyaron la causa independentista, sin grandes resultados. En un decreto que se expidió en Carúpano, Bolívar llamó al servicio militar a todos los hombres esclavizados de 14 a 70 años de edad a cambio de su libertad y la de sus familias. Pero si éstos no se integraban al ejército, perderían el derecho a ser ciudadanos de la República de Venezuela.

53 En particular se basó en las leyes de Antioquia y Venezuela. 
Popayán la forma más común de manumisión en el siglo XIX fue la autocompra o compra por un tercero ${ }^{54}$. En la década de 1840 Colombia tuvo su primera guerra civil, la Guerra de los Supremos. En esta guerra el principal caudillo de Popayán, José María Obando, nuevamente movilizó a los esclavos de las haciendas con la promesa de liberación. Esta fue una de las últimas fases en la larga y compleja lucha por la abolición en Colombia. En 1851, durante el gobierno de José Hilario López, finalmente se decretó el fin de la esclavitud ${ }^{55}$. Aunque la principal meta de los esclavizados durante la primera mitad del siglo XIX fue acabar con la esclavitud, en Colombia no hubo una alianza racial entre la gente de ascendencia africana. Ésta es un área de investigación que necesita más atención. Si se supera la división entre las historiografías de la resistencia entre los esclavos y de la política de los pardos o negros libres, se podrá comprender la manera en que la política racial determinó las dinámicas políticas y militares en el contexto republicano.

El proceso político que vivieron las comunidades indígenas que defendieron a la Corona durante la guerra determinó sus dinámicas internas una vez alcanzada la independencia. Si algunos indios del común vieron como beneficiosa la abolición del tributo en la negociación con los realistas tal vez también hubieran estado interesados en algunas de las medidas propuestas por Bolívar. Sin embargo, dada la fortaleza de los caciques desde la reinstauración del absolutismo 1814 y 1820, en el resto del siglo las comunidades defendieron su estatus como indios y sus tierras comunales ${ }^{56}$. En este proceso las comunidades del suroccidente colombiano apelaron a una forma específica de ciudadanía, reivindicando un tipo de republicanismo que no negaba su identidad indígena sino que intentaba protegerla dentro de la nueva nación ${ }^{57}$.

Como se ha dicho, las alianzas entre la gente de ascendencia africana esclavizada y las elites realistas en Popayán obligan a ampliar el lente de análisis cuando se trata de establecer vínculos entre los subalternos y el republicanismo. Pero, por otra parte, esas alianzas no significaron que los grupos previamente declarados realistas fueran aliados potenciales de los conservadores. En realidad, en Colombia los negros libres fueron incorporados por el Partido Li-

\footnotetext{
54 Arboleda, 2006: 19.

55 La movilización de los esclavos que caracterizó las décadas de 1830 y 1840 en Popayán, por medios legales o militares, ha sido estudiado por Díaz, 2007.

56 Sobre la reacción de los indios a medidas similares en los Andes, véanse Hünefeldt, 11-12 (Cusco, 1978): 33-57. Irurozqui, LIX/217 (Madrid: 1999): 707-740. Sala i Vila, 39-40 (Barcelona, 1990): 203-226.

57 Sanders, 26 (Bogotá, 2007): 29-45.
} 
beral a la política electoral al desarrollar éste un discurso racial incluyente ${ }^{58}$. En consecuencia, si el realismo no debe verse necesariamente como un antecesor del conservadurismo moderno, la división entre liberales y conservadores, normalmente adscrita a las luchas entre las elites, puede observarse de manera más fluida al incluirse en su comprensión las luchas populares que datan del proceso de independencia.

\section{BIBLIOGRAFÍA}

Andrien, Kenneth, «Soberanía y Revolución en el Reino de Quito, 1809-1810», Ponencia presentada en el Seminario Internacional En el umbral de las revoluciones hispánicas: El bienio 1808-1810, El Colegio de México, abril 10-11, 2008.

Arboleda, Juan Ignacio, «Entre la libertad y la sumisión. Estrategias de libertad de los esclavos en la gobernación de Popayán durante la independencia, 1808-1830», Bogotá, Universidad de Los Andes, 2006.

Baber, Jovita, «The Construction of Empire: Politics, Law and Community in Tlaxcala, New Spain, 1521-1640», Tesis doctoral, University of Chicago, 2005.

Bastidas, Edgar, Las guerras de Pasto, Pasto, Ediciones Testimonio, 1979.

Bennett, Herman, Africans in Colonial Mexico: Absolutism, Christianity, and Afro-Creole Consciousness, 1570-1640, Bloomington, Indiana University Press, 2003.

Benton, Lauren, Law and Colonial Cultures: Legal Regimes in World History, 1400-1900, New York, Cambridge University Press, 2002.

Blackburn, Robin, The Overthrow of Colonial Slavery, 1776-1848 [1988], New York, Verso, 2000.

Blanchard, Peter, Under the Flags of Freedom: Slave Soldiers \& the Wars of Independence in Spanish South America, Pittsburg, Pittsburgh University Press, 2008.

Borah, Woodrow, Justice by Insurance: The General Indian Court of Colonial Mexico and the Legal Aides of the Half Real, Berkeley, University of California Press, 1983.

Bryant, Sherwin, «Enslaved Rebels, Fugitives, and Litigants: The Resistance Continuum in Colonial Quito», Colonial Latin American Review 13/1 (Londres, 2004): 7-46.

Brown, Matthew, «Esclavitud, castas y extranjeros en las guerras de la Independencia de Colombia», Historia y Sociedad, 10 (Medellín, 2004): 109-125.

\footnotetext{
58 Sanders, 2004.
} 
Cañeque, Alejandro, The King's Living Image: The Culture and Politics of Viceregal Power in Colonial Mexico, New York, Routledge, 2004.

Chávez, María Eugenia, Honor y Libertad. Discursos y recursos en la estrategia de libertad de una mujer esclava (Guayaquil a fines del periodo colonial), Gotemburgo, Iberoamerican Institute of the University of Gothenburg, 2001.

Childs, Matt, The 1812 Aponte Rebellion in Cuba and the Struggle against Atlantic Slavery, Chapel Hill, University of North Carolina Press, 2006.

Chust, Manuel, «De esclavos, encomenderos y mitayos. El anticolonialismo en las Cortes de Cádiz», Mexican Studies/Estudios Mexicanos, 11/2 (Berkeley, 1995): 179-202.

Congreso de Cúcuta de 1821. Constitución y Leyes, Bogotá, Biblioteca Banco Popular, 1971.

Cutter, Charles, The Protector de Indios in Colonial New Mexico, 1659-1821, Albuquerque, University of New Mexico Press, 1986.

De Armellada, Cesáreo, La Causa Indígena Americana en las Cortes de Cádiz, Caracas, Universidad Católica Andrés Bello, 1979.

De la Fuente, Alejandro, «"Su único derecho”: los esclavos y la ley», Debate y Perspectivas, 4 (Madrid, 2004): 7-22.

Díaz, María Camila, «"Salteadores y cuadrillas de malhechores”: Una aproximación a la acción colectiva de la población negra en el suroccidente de la Nueva Granada, 1840-1851», Tesis de pregrado, Universidad Javeriana, 2007.

Documentos Importantes de Nueva Granada, Colombia y Venezuela (Apéndice de la Historia de Colombia, Tomo V), escogidos por José Manuel Restrepo, [1861] Bogotá, Imprenta Nacional, 1969.

Dubois, Laurent, «Citizen Soldiers: Emancipation and Military Service in the Revolutionary French Caribbean», Christopher Brown (ed.), Arming Slaves: From Classical Times to the Modern Age, New Haven y Londres, Yale University Press, 2006: 233-254.

Earle, Rebecca, «Indian Rebellion and Bourbon Reform in New Granada: Riots in Pasto, 1780-1800», Hispanic American Historical Review 73:1 (Durham, 1993): 99-124.

Earle, Rebecca, "Creole Patriotism and the Myth of the "Loyal Indian"», Past and Present 172 (Oxford, 2001): 125-145.

Echeverri, Marcela, «Conflicto y hegemonía en el suroccidente de la Nueva Granada, 1780-1800», Fronteras de la Historia 11 (Bogotá, 2006): 343-376.

Friede, Juan, El indio en lucha por la tierra. Historia de los resguardos del macizo colombiano [1944], Bogotá, Editorial La Chispa, 1972. 
Geggus, David, «Slavery, War, and Revolution in the Greater Caribbean», David Gaspar y David Geggus, A Turbulent Time: The French Revolution and the Greater Caribbean, Bloomington e Indianápolis, Indiana University Press, 1997: 1-50.

Guerrero, Gerardo León, Pasto en la guerra de independencia, 1809-1824, Bogotá, Tecnoimpresores, 1994.

Guerrero, Gustavo, Documentos históricos de los hechos ocurridos en Pasto en la Guerra de Independencia, Pasto, Imprenta del Departamento, 1912.

Gutiérrez, Jairo, Los indios de Pasto contra la República (1809-1824), Bogotá, ICANH, 2007.

Gutiérrez, Jairo, «La Constitución de Cádiz en la provincia de Pasto, Virreinato de la Nueva Granada, 1812-1822», Revista de Indias LXVIII/242 (Madrid, 2008): 207-224.

Hespanha, Antonio, La gracia del derecho. Economía de la cultura en la Edad Moderna, Madrid, Centro de Estudios Políticos y Constitucionales, 1993.

Hünefeldt, Christine, «Los indios y la Constitución de 1812», Allpanchis 11-12 (Cusco, 1978): 33-57.

Irurozqui, Marta, «Las paradojas de la tributación. Ciudadanía y política estatal indígena en Bolivia, 1825-1900», Revista de Indias LIX/217 (Madrid: 1999): 707-740.

Irurozqui, Marta, «El bautismo de la violencia. Indígenas patriotas en la revolución de 1870 en Bolivia», Josefa Salmón y Guillermo Delgado, Identidad, ciudadanía y participación popular desde la colonia al siglo XX, La Paz, Editorial Plural, 2003: $115-152$.

Irurozqui, Marta, «Los hombres chacales en armas: Militarización y criminalización indígenas en la revolución federal boliviana de 1899», Marta Irurozqui (ed.), $L a$ Mirada Esquiva. Reflexiones sobre la interacción del estado y la ciudadanía en los Andes (Bolivia, Ecuador y Perú), siglo XIX, Madrid, Consejo Superior de Investigaciones Científicas, 2005: 285-320.

Kuethe, Allan, Military Reform and Society in New Granada, 1773-1808, Gainesville, The University Presses of Florida, 1978.

Lucena Salmoral, Manuel, Sangre sobre piel negra. La esclavitud quiteña en el contexto del reformismo borbónico, Quito, Centro Cultural Afroecuatoriano, Ediciones Abya-Yala, Colección Mundo Afro 1, 1994.

Lucena Salmoral, Manuel, Los códigos negros de la América española, Ediciones Unesco/Universidad de Alcalá, 1996.

Macías, Flavia, «Ciudadanía armada, identidad nacional y estado provincial. Tucumán, 1854-1870», Hilda Sábato y Alberto Lettieri, La vida política en Argentina del siglo XIX. Armas, votos y voces, Buenos Aires, Siglo XXI, 2003: 137-152. 
Méndez, Cecilia, The Plebeian Republic: The Huanta Rebellion and the Making of the Peruvian State, 1820-1850, Durham, Duke University Press, 2005a.

Méndez, Cecilia, «Tradiciones liberales en los Andes o la ciudadanía por las armas: Campesinos y militares en la formación del estado peruano», Marta Irurozqui (ed.), La Mirada Esquiva. Reflexiones sobre la interacción del estado y la ciudadanía en los Andes (Bolivia, Ecuador y Perú), siglo XIX, Madrid, Consejo Superior de Investigaciones Científicas, 2005b: 125-154.

Miramón, Alberto, «Agualongo, el guerrillero indomable», Boletín de Historia y Antigüedades, 27/313-314 (Bogotá, 1940): 968-985.

Morelli, Federica, Territorio o Nación. Reforma y disolución del espacio imperial en Ecuador, 1765-1830, Madrid, Centro de Estudios Políticos y Constitucionales, 2005.

Ortiz, Sergio Elías, Agustín Agualongo y su tiempo, Bogotá, Editorial A.B.C., 1958.

Ots y Capdequí, José María, Manual de Historia del Derecho Español en las Indias y del Derecho Propiamente Indiano, Buenos Aires, Instituto de Historia del Derecho Argentino, 1943.

Owensby, Brian, «How Juan and Leonor Won Their Freedom: Litigation and Liberty in Seventeenth-Century Mexico», Hispanic American Historical Review 85:1 (Durham, 2005): 39-80.

Peralta, Víctor, «El mito del ciudadano armado. La "semana magna" y las elecciones de 1844 en Lima», Hilda Sábato (ed.), Ciudadanía política y formación de las naciones. Perspectivas históricas en América Latina, México, FCE, 1999, pp. 231-252.

Platt, Tristán, Estado Boliviano y ayllu andino: tierra y tributo en el Norte de Potosí, Lima, Instituto de Estudios Peruanos, 1982.

Premo, Bianca, Children of the Father King: Youth, Authority and Legal Minority in Colonial Lima. Chapell Hill, The University of North Carolina Press, 2005.

Rappaport, Joanne, The Politics of Memory: Native Historical Interpretation in the Colombian Andes, Durham, Duke University Press, 1998.

Restrepo, José Manuel, Diario Político y Militar. Memorias sobre los sucesos importantes de la época para servir a la historia de la revolución de Colombia y de la Nueva Granada, desde 1819 para adelante, vol. I, Bogotá, Imprenta Nacional, 1854.

Ricketts, Mónica, «The Institutional Foundations of Bourbon Military Success in Peru and Its Long-Lasting Political Consequences», Trabajo presentado en el Seminario Internacional del Mundo Atlántico, Harvard University, agosto 3-14, 2008.

Revista de Indias, 2009, vol. LXIX, n. ${ }^{\circ} 246,45-72$, ISSN: 0034-8341 doi: 10.3989/revindias.2009.012 
Rodríguez, Jaime, «Las primeras elecciones constitucionales en el Reino de Quito, 1809-1814 y 1821-1822», Procesos. Revista Ecuatoriana de Historia 14 (Quito, 1999): 3-52.

Rodríguez, Jaime, La revolución política durante la época de la independencia. El Reino de Quito, 1808-1822, Quito, Universidad Andina Simón Bolívar, Corporación Editora Nacional, 2006.

Saether, Steinar, Identidades e Independencia en Santa Marta y Riohacha, 1750-1850. Bogotá: Instituto Colombiano de Antropología e Historia, 2005a.

Saether, Steinar, «Independence and the Redefinition of Indianness around Santa Marta, Colombia, 1750-1850», Journal of Latin American Studies 37 (Cambridge, 2005b): 55-80.

Sala i Vila, Nuria, «El levantamiento de los pueblos de Aymaraes en 1818», Boletín Americanista 39-40 (Barcelona, 1990): 203-226.

Sanders, James, Contentious Republicans: Popular Politics, Race, and Class in Nineteenth-Century Colombia, Durham, Duke University Press, 2004.

Sanders, James, «Pertenecer a la gran familia granadina. Lucha partidista y construcción de la identidad indígena política en el Cauca, Colombia, 1849-1890», Revista de Estudios Sociales 26 (Bogotá, 2007): 29-45.

Solórzano y Pereyra, Juan, «De los privilegios y gracias que a los indios, por miserables y recién convertidos, les están concedidas en las causas materiales y espirituales», Politica Indiana, Madrid, Ediciones de la Fundación José Antonio de Castro, 1996.

Stern, Steve, Peru's Indian Peoples and the Challenge of the Spanish Conquest, [1982] Madison, University of Wisconsin Press, 1991.

Thomson, Sinclair, We Alone Will Rule: Native Andean Politics in the Age of Insurgency, Madison: University of Wisconsin Press, 2002.

Tovar, Hermes, Convocatoria al poder del número. Censos y estadísticas de la Nueva Granada, 1750-1850, Bogotá, Archivo General de la Nación, 1994.

Walker, Charles, Smoldering Ashes: Cuzco and the Creation of Republican Peru, 1780-1840, Durham, Duke University Press, 1999.

Williams, Derek, Acomodación, negociación y el actuar político. Resistencia y revuelta indígena en el altiplano de los Pastos, Cali, Tesis de Maestría, Universidad del Valle, 1994.

Williams, Derek, «"Who Induced the Indian Communities?” The Los Pastos Uprising and the Politic of Ethnicity and Gender in Late-Colonial New Granada», Colonial Latin American Historical Review, 10:3 (Albuquerque, 2001): 277-309. 


\section{THE RIGHTS OF ROYALIST INDIANS AND SLAVES AND THE POLITICAL TRANSFORMATION OF POPAYAN, NEW GRANADA (1808-1820)}

This article focuses on the strategic interpretation and defense of royalist discourse by Indians and slaves in Popayan, New Granada, between 1808 and 1820. During the crisis of the Spanish Monarchy, both Indians and slaves attempted to gain benefits from the political context and particularly to give new shape to their rights by becoming allies of the royalists. Through a study of those alliances and highlighting the complex social articulation and political participation of Indians and slaves in the political transformation that was underway in this period, this work argues that popular royalism was dynamic and fluid.

Key words: Royalism, Indians, Slaves, Rights, Pact, Freedom, Liberalism. 